\title{
Orgullo del barRio: Marchas populares y transformación URbana en LISBOA
}

\author{
Iñigo Sánchez Fuarros ${ }^{1}$ \\ Universidade Nova de Lisboa, Portugal
}

\begin{abstract}
Esta serie fotográfica retrata el día a día de la preparación de la Marcha de la Mouraria del año 2017, una práctica cultural enraizada en la vida cotidiana de los barrios populares de Lisboa, asociada a la construcción de la identidad local y espacio de expresión de un fuerte sentimiento de pertenencia al barrio. Este ensayo visual quiere poner el acento en la capacidad de resiliencia de un conjunto de vecinos y jóvenes que, congregados en torno a una institución con más de ocho décadas de historia, el Grupo Desportivo da Mouraria, renuevan cada año su compromiso por mantener viva la tradición de las marchas populares frente a los desafios que plantea la rápida transformación urbana de Lisboa y de sus barrios populares.
\end{abstract}

Palabras llave: cultura expresiva, marchas populares, Lisboa, fotografía, turismo, renovación urbana

Al grito de "Carrega Mouraria!” (¡Vamos Mouraria!) todo un barrio se pone en marcha. ${ }^{2}$ En la víspera de la noche de San Antonio, veinticuatro parejas de hombres y mujeres, acompañadas de músicos, aguadeiros, portaestandarte, padrinos y "mascotas”, uniformados y portando diversos elementos escenográficos, descienden la Avenida de la Libertad en representación del barrio de la Mouraria. Son una más de la veintena de marchas que participan en el desfile de

1 Contacto: ifuarros@gmail.com

2 Me gustaría expresar mi agradecimiento a la comisión organizadora de la Marcha de la Mouraria, a los marchantes y a los responsables del Grupo Desportivo da Mouraria, por permitirme acompañarles y ser testigo de primera mano de su esfuerzo, dedicación y pasión por las marchas populares. También quisiera agradecer a los compañeros y profesores del colectivo de fotógrafos Hélice por proporcionar un espacio crítico para pensar y reflexionar sobre mi práctica fotográfica. 
las Marchas Populares, con el que se abre oficialmente los festejos de la noche más larga de la capital portuguesa. En los laterales de la avenida, tras las vallas de protección o sentados en las gradas instaladas para la ocasión, vecinos y simpatizantes animan a los marchantes durante el trayecto: “Ié, ié, ié, a Mouraria é que é!”; “A Mouraria é linda!" La participación en el desfile supone para los marchantes y la comisión organizadora la culminación de varios meses de planificación, preparación y ensayos diarios en los que un barrio modesto como el de la Mouraria moviliza recursos humanos y materiales para producir una marcha que encarne, en sus propios términos, el carácter, los valores y las tradiciones del barrio, y al mismo tiempo aspire a ganar el concurso, algo que no sucede desde el año 1981.

\section{Para ver la galería de fotos, consulte el artículo online aquí:} https://journals.openedition.org/cadernosaa/1414

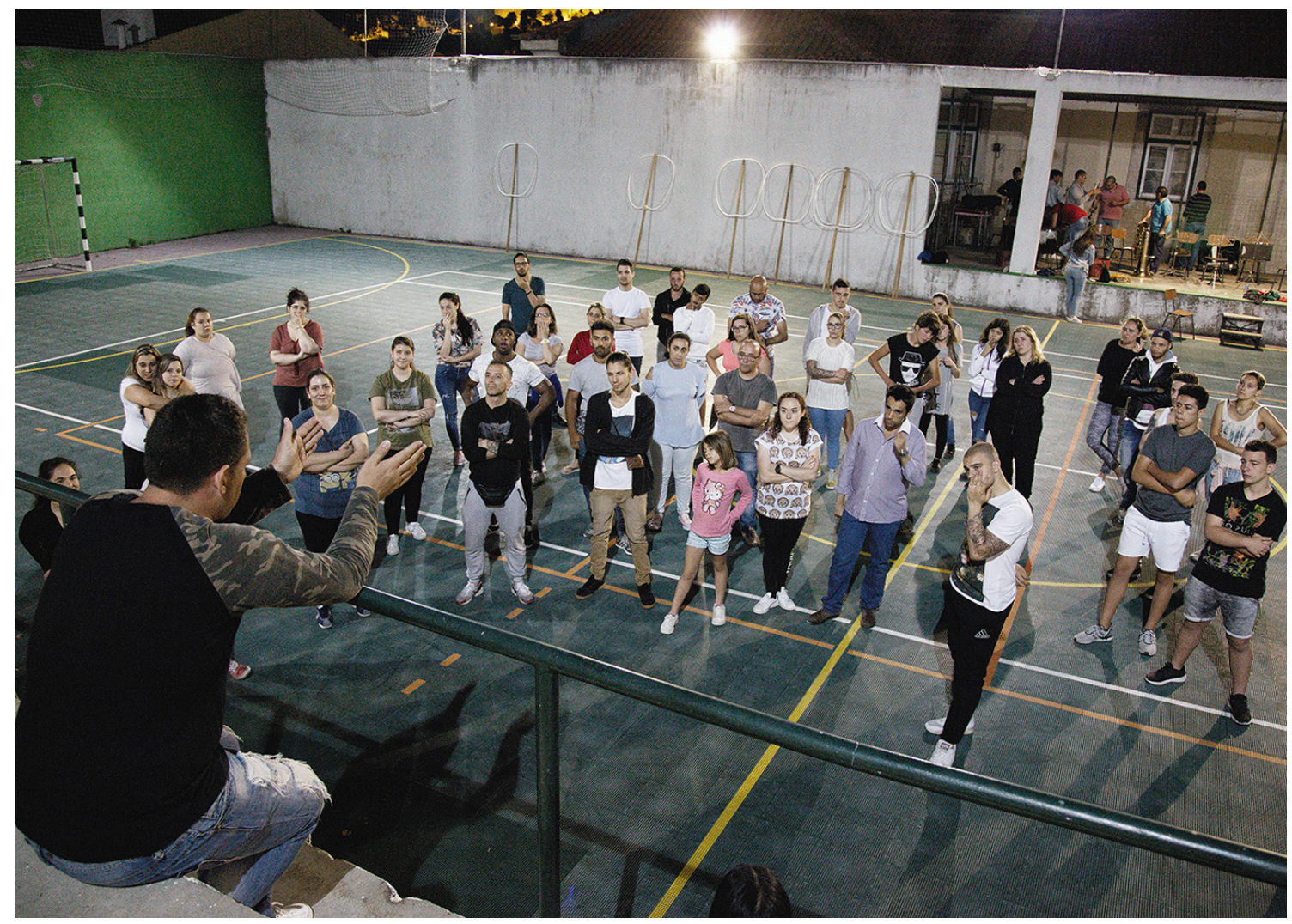

Este conjunto de fotografías funciona a modo de diario visual del día a día de la Marcha de la Mouraria del año 2017: desde los ensayos hasta el momento culminante del desfile final pasando por los bastidores de la marcha, habitualmente vetados a observadores externos. Este trabajo es fruto de varios años acompañando a la Marcha de la Mouraria como antropólogo y fotógrafo y es parte de un proyecto de investigación más amplio que estudia el impacto del proceso de revitalización urbana de la Mouraria en el entorno sonoro del barrio (Sánchez Fuarros 2015, 2016, 2017a). ${ }^{3}$ Frente a la imagen habitual de barrio envejecido y parado en el tiempo, cuya supervivencia parece amenazada hoy por el empuje del turismo y la gentrificación, este conjunto de fotografías pretende destacar el empeño y vitalidad de un grupo de hombres y mujeres de la Mouraria, mayoritariamente jóvenes, por continuar la tradición de las marchas

3 Esta colaboración con la Marcha de la Mouraria ha resultado en varios proyectos fotográficos expuestos en el barrio, que pueden ser consultados en la siguiente URL: http://www.inigosanchez.com. 
populares. Al mismo tiempo es una invitación a reflexionar sobre la relevancia de estas prácticas culturales en la producción de un sentido de comunidad y un sentimiento de pertenencia al barrio en una coyuntura como la actual, marcada por rápidos cambios en la configuración social y urbana de los barrios populares de Lisboa.

\section{II}

La expulsión de la población local y los cambios en la fisionomía y usos del espacio urbano son quizás dos de los efectos más visibles de la rápida transformación de Lisboa en destino turístico, una transformación retratada incisivamente (y con un cierto humor) por el colectivo Left Hand Rotation en un reciente documental titulado Terramotourism. ${ }^{4} \mathrm{El}$ aumento del precio del acceso a la vivienda, la proliferación de hoteles y apartamentos turísticos o la sustitución del comercio local por negocios orientados al turismo están transformando de forma significativa el tejido urbano y social de los barrios históricos del centro de la capital portuguesa. ${ }^{5}$ En algunas zonas, como en el turístico barrio del Castelo, los residentes permanentes apenas llegan a unas pocas centenas mientras que el número de turistas no deja de aumentar. En otros más castizos, como los barrios aledaños de Alfama y Mouraria, los vecinos con arraigo en el territorio corren el peligro de convertirse en una especie en peligro de extinción, transformados de forma involuntaria en figurantes de una Lisboa de cartón-piedra que ha convertido su "tipicidad" en valor de cambio para el turista foráneo que busca experiencias de "autenticidad".

Pero no son estas las únicas consecuencias de la transformación de Lisboa en ciudad-mercancía (Malet Calvo 2017). Amenazada por las fuerzas homogeneizadoras de la rehabilitación urbana se encuentra también esa sutil trama de relaciones entre personas, cosas y prácticas que configura las maneras de hacer de la vida cotidiana que han caracterizado tradicionalmente a los barrios populares lisboetas. Este ensayo visual se adentra en uno de estos barrios, el barrio de la Mouraria, y se aproxima a unas instituciones (las colectividades ${ }^{6}$ ) y a una práctica cultural (las marchas populares) que históricamente han desempeñado un papel destacado en la articulación de vínculos sociales fuertes y duraderos dentro de los barrios, constituyéndose como una poderosa práctica productora de identidad(es) bairristas (Firminho da Costa 1999). ${ }^{7}$

$4 \quad$ El documental puede ser consultado en la siguiente URL: https://vimeo.com/191797954 [Fecha de consulta: $28 / 02 / 2018]$

5 Un reciente estudio encargado por los distritos de Santa Maria Maior, Misericórdia y São Vicente alerta precisamente sobre los efectos negativos de estas nuevas dinámicas en el centro histórico de Lisboa. http://www. quaternaire.pt/Destaques/Novas-Dinamicas-Residenciais-Economicas-e-Urbanisticas-no-Centro-Historicode-Lisboa [Fecha de consulta: 28/02/2018]

6 Las colectividades (también conocidas como associações recreativas) son asociaciones de barrio creadas, en la mayoría de los casos, durante el periodo del Estado Novo (nombre que recibe el régimen político autoritario y corporativista que gobernó Portugal entre 1933 y 1974) y que históricamente han jugado un papel importante en la dinamización y estructuración de los grupos sociales en los barrios populares de Lisboa (véase Índias Cordeiro 2010).

7 En la introducción a su etnografía sobre el barrio de Bica en Lisboa, Graçã Índias Cordeiro (1997:21 y ss.) define el bairrismo como un sentimiento de pertenencia a los barrios típicos o populares de la capital portuguesa que se moviliza sobre todo en situaciones especialmente ritualizadas como pueden ser las fiestas de los santos populares o las marchas. En el contexto español, esta manera de vivir y referirse a la pertenencia a un barrio como seña de identidad aparece recogida en el reciente Diccionario de las periferias. Métodos y saberes autónomos desde los barrios (2017) bajo el término "barrionalismo". 
Creadas en la década de los años 30 del siglo pasado como un intento de modernizar las fiestas de los santos populares del mes de junio, las marchas populares constituyen el punto álgido de las celebraciones del día de San Antonio, patrón de la ciudad. "Cruce peculiar de influencias rurales y urbanas pasadas por el tamiz de la folklorización”, en palabras del historiador Daniel Melo (2003), las marchas populares adoptaron desde muy temprano la forma de una competición tutelada por las autoridades municipales, en la que los barrios de la capital competían por ver quién representaba mejor su propia idiosincrasia. Cada barrio es representado por una marcha que es a su vez organizada por una colectividad representativa de ese territorio. La competición adopta la forma de un desfile en dos tiempos. El primero transcurre en un pabellón cubierto donde cada barrio interpreta un programa que incluye tres marchas libres, inspiradas en algún tema que apela a las tradiciones culturales asociadas con ese territorio (por ejemplo, el fado o la figura de la Severa, en el caso de la Mouraria), y una cuarta marcha que es común para todos los participantes, la "Gran Marcha de Lisboa". El carácter de cada barrio se pone en escena a través de una serie de elementos como son la música, la letra de las canciones, el vestuario, la coreografía y el diseño de la escenografía (arcos, sorpresa, etc.), elementos todos ellos que son cuidadosamente evaluados por un jurado conforme a un reglamento tan complejo como minucioso. El segundo desfile se celebra la víspera del día de San Antonio y tiene como escenario la emblemática Avenida de la Libertad de la capital portuguesa, siendo además retransmitido en directo por la televisión pública.

Esta "tradición inventada", siguiendo la formulación acuñada por Hobsbawm (Hobswam 2012), posee un doble valor. Por un lado, las marchas junto con las colectividades que las organizan, se asumen como entidades que representan a los barrios fuera de sus límites, valiéndose de una imagen idealizada e mitificada de los mismos que con frecuencia acude al pasado en busca de elementos de identificación. Por el otro, el espacio real y simbólico de la marcha interpela a su vez al barrio y a sus dinámicas propias a partir de una densa red de relaciones sociales, afectos, alianzas y constelaciones familiares que entran a formar parte del espacio de la marcha. Las marchas populares se configuran así como una poderosa práctica identitaria de los barrios populares, lugar privilegiado de afirmación de un sentimiento de pertenencia al territorio y de valorización de una identidad bairrista propia (véase Firminho da Costa 1999; Cordeiro 1997; Menezes 2004).

IV

En el actual proceso de cambio y transformación por el que atraviesa la ciudad de Lisboa, marcado por la turistificación y elitización de sus barrios populares, la pérdida de población y el progresivo deterioro de los vínculos locales y relaciones de vecindad, cabe preguntarse acerca de la relevancia social de una práctica cultural como la de las marchas populares, y en particular sobre su función como dispositivo generador de vínculos sociales entre las clases populares de estos territorios. El barrio de la Mouraria no ha escapado a este proceso. Objeto de un intenso programa municipal de revitalización urbana entre los años 2011 y 2013 que buscaba transformar este barrio maldito y de mala reputación en una zona atractiva para el turismo, la inversión privada y nuevos residentes (véase Sánchez Fuarros 2017a), la Mouraria es hoy, como el resto de los barrios históricos lisboetas, un terreno fértil para la especulación inmobiliaria, donde proli- 
feran los edificios de alojamiento turístico, las nuevas promociones inmobiliarias destinadas a la inversión extranjera y una población fluctuante sin raíces en el territorio.

A pesar de ello, el calendario de las marchas populares continúa marcando el ciclo anual de la vida cotidiana del barrio: desde el mes de marzo, cuando se presenta la marcha, hasta finales del mes de junio, cuando se da por concluida la temporada con la vuelta al barrio y una cena de confraternización de los marchantes. Abril, mayo y junio son meses de ensayos diarios, en los que el repetitivo sonido del cavalinho y las voces de los marchantes resuenan cada noche en el barrio. La marcha conservan aún hoy una gran importancia simbólica en la producción de la identidad local, una importancia que los marchantes expresan habitualmente apelando a un sentimiento tan poderoso como es el del orgullo: orgullo de ser de la Mouraria, orgullo de representar al barrio, orgullo de ir en la marcha... En definitiva, orgullo bairrista. ${ }^{8}$

Este conjunto de imágenes no pretende proyectar así una imagen nostálgica sobre una práctica demodé. Antes bien, este ensayo visual quiere poner el acento en la capacidad de resiliencia de un conjunto de vecinos y jóvenes que, congregados en torno a una institución con más de ocho décadas de historia, el Grupo Desportivo da Mouraria, renuevan cada año su compromiso por mantener viva la tradición de las marchas populares frente a los desafíos que plantea la rápida transformación urbana de Lisboa y de sus barrios populares.

\section{Referencias}

Cordeiro, Graça Indias. 2010. “Associaçoes recreativas”. Pp. 82-83 en Enciclopédia da música em Portugal no século XX, coordinada por Salwa El-Shawan Castelo Branco, Lisboa: Circulo de Leitores.

- 1997. Um lugar na cidade. Quotidiano, Memória e Representação no Bairro da Bica. Lisboa: Publicações Dom Quixote.

Firmino da Costa, António. 2008. Sociedade de Bairro. Dinâmicas Sociais da Indentidade Cultural. Lisbon: Celta editora.

Hobsbawn, Eric. 2012. "Introduction: Inventing Traditions". Pp. 1-14 en The Invention of Tradition, editado por Eric Hobsbawn y Terence Ranger, Cambridge: Cambridge University Press.

Malet Calvo, Daniel. 2017. "Lisboa, genealogía de un colapso turístico". Seres Urbanos, El País, 16 de Febrero. Fecha de consulta: 01/03/2018 <https://elpais.com/elpais/2017/02/07/seres_urbanos/1486483821_363384.html>

Melo, Daniel 2003: “As Marchas Populares: a encenação da cidade de Lisboa”. Pp. 307-322 en Vozes de Povo. A Foklorizaçâo em Portugal, editado por Salwa El-Shawan Castelo Branco y Jorge Freitas Branco, Oeiras: Celta editora.

Menezes, Marluzi. 2004. Mouraria, Retalhos de um imaginário. Significados urbanos de um bairro de Lisboa. Lisboa: Celta editora.

8 “Qué sientes cuando marchas representando a la Mouraria?” fue la pregunta que sirvió de hilo conductor al video A marcha não se explica, sente-se (Sánchez Fuarros 2017b) en el que los marchantes refieren a toda una variedad de sentimientos que su participación en la marcha moviliza, además del de orgullo. El vídeo puede ser visto en la siguiente URL: https://inigosanchez.com/audiovisual/a-marcha-nao-se-explica-sente-se/ [Fecha de consulta: 01/03/2018]. 
Sánchez Fuarros, Iñigo. 2017a. "Mapping Out the Sounds of Urban Transformation: The Renewal of Lisbon's Mouraria Quarter". Pp. 153-167 en Toward an Anthropology of Ambient Sound, editado por Christine Guillebaud, Nueva York: Routledge.

—. 2017b. "A marcha não se explica, sente-se". Vimeo, 14:03, subido el 15 de mayo, <https:// vimeo.com/221161119>

- 2016 "Ai, Mouraria! Music, Tourism and Urban Renewal in a Historic Lisbon Neighbourhood". MUSICultures. 43(2): 66-88.

— 2015. "De barrio maldito a destino "cool". El papel de la música en la rehabilitación urbana de un barrio tradicional lisboeta: la Mouraria". In/mediaciones de la Comunicación 10: $20-34$

VV.AA. 2017. Diccionario de las periferias. Métodos y saberes autónomos desde los barrios. Madrid: Traficante de Sueños.

\section{NEIGHBOURHOOD'S PRIDE: POPULAR MARCHES AND URBAN TRANSFORMATIONS IN Lisbon, Portugal}

This photography essay depicts the preparations of the Marcha da Mouraria of 2017, a cultural practice ingrained in the daily life of Lisbon's traditional neighbourhoods which is related to the production of local identities and provides a space for the expression of a strong sense of belonging to the one's neighbourhood. This essay highlights the resilience of a group of local residents and youth who year by year gather around the Grupo Desportivo da Mouraria, a local association with more than eight decades of history, to renew their commitment of keeping the tradition of the "marchas populares" (popular parades) alive in the midst of the rapid urban transformation which the city of Lisbon and its traditional neighbourhoods are currently experiencing.

Keywords: expressive culture, marchas populares, Lisbon, photography, tourism, urban renewal

Data recibido: $2017-08-23$

Data aceptado: 2018-03-05 